\title{
La carne y la metáfora: una reflexión sobre el cuerpo en la teoria queer. Gerard Coll-Planas, Madrid: Egales, 2012. 108 pp.
}

\author{
Antar Martínez-Guzmán ${ }^{1}$ \\ Universidad de Colima ${ }^{2}$ \\ antar_martinez@ucol.mx
}

Doctor en Psicología Social de la Universidad Autónoma de Barcelona.

Profesor de la Facultad de Psicología.

Documento accesible en línea desde la siguiente dirección: http://revistas.javeriana.edu.co

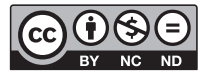


El cuerpo se ha convertido en un tema central de discusión en el ámbito de las ciencias sociales y humanas. El creciente interés que el cuerpo genera deriva del hecho de que, cada vez con mayor claridad, este se vuelve territorio en disputa, campo de batalla donde distintos proyectos políticos se ponen en juego. Es por ello también que el cuerpo se convierte en el punto desde el cual desembocan ontologías sociales, biológicas, médicas, jurídicas, etc.

Es en este encendido debate sobre la comprensión del cuerpo y las fuerzas que lo constituyen donde se sitúa La carne y la metáfora: Una reflexión sobre el cuerpo en la teoría queer de Gerard Coll-Planas. Esta obra es en principio, una invitación a reflexionar de manera crítica sobre el papel que las teorizaciones y prácticas queer dan al cuerpo y en términos generales, sobre el cuerpo como objeto de producción y consumo promovido por el capitalismo contemporáneo.

En el primer apartado titulado "Invitación", Coll-Planas conmina a quien lee a asumir una autoria compartida y a generar una andadura cómplice e inquisitiva a través de los vericuetos que el libro propone. En el segundo capítulo, "El cuerpo consumido", se analizan los cuerpos paradójicos de nuestro tiempo: anclajes de la identidad y al mismo tiempo ficciones fragmentadas y mercantilizadas. Se muestra la forma en que la sociedad contemporánea rechaza y oculta la mortalidad, la precariedad y la fragilidad del cuerpo al tiempo que alimenta la fantasía de un cuerpo ilimitado y todopoderoso. Para hacerlo recurre a la teoria social (Bauman y Elias, por ejemplo), pero igualmente echa mano de series de televisión, personajes de la farándula, elementos de arte corporal y obras de performers como Abramovic y Sterlac. Esta noción del cuerpo como infinitamente moldeable e ilimitado, servirá posteriormente a Coll-Planas para argumentar que, al menos una parte de la teoría y el activismo queer no funcionan tanto como formas de subversión, sino como mecanismos de reproducción de las formas hegemónicas de representación del cuerpo.

Ante la imagen de un cuerpo idealizado e inmune, Coll-Planas nos devuelve un cuerpo de carne y hueso, doliente y sangrante, un cuerpo vulnerable que sigue siendo blanco de violencias aterradoras. Para ilustrar esta condición, el tercer capítulo, "La carne", desmenuza la trama del brutal asesinato de dos chicos gays en Vigo (Cataluña), un acontecimiento real que Coll-Planas utiliza para mostrar el cuerpo en su encarnada fragilidad, atravesado por feroces constreñimientos políticos y materiales. 
En la cuarta parte, "La metáfora", Coll-Planas discute la perspectiva de la teoría y el activismo queer sobre el cuerpo. Realiza una caracterización esquemática de la perspectiva queer en la que expone sus ejes centrales sin dejar de recoger algunas críticas que se le han formulado. Desarrolla, de manera sucinta pero lúcidamente clara, la muchas veces malentendida idea de que el lenguaje da forma al cuerpo, haciendo un breve repaso a la manera en que distintas posiciones constructivistas conciben el papel del lenguaje en la construcción de la realidad. De manera particular, Coll-Planas advierte sobre los riesgos de sobredimensionar el papel del lenguaje para desatender las condiciones efectivamente materiales en que se desarrollan nuestras vidas.

Al adentrarse a la concepción queer sobre el cuerpo, Coll-Planas advierte que es posible identificar a dos Butlers, dos lecturas distintas y comunes de la obra de esta autora tan frecuentemente mitificada. Estas dos lecturas abren paso a dos rutas distintas -y por momentos opuestas- en la comprensión queer del cuerpo.

En la primera de ellas, el cuerpo aparece despojado de su materialidad, de sus limites y de sus fragilidades. En consonancia con la lógica neoliberal del self-made-man, se presenta un cuerpo que se construye al antojo, que se puede moldear a conveniencia; un cuerpo que es objeto de producción y consumo, "donde el lenguaje ahoga la materialidad". Esta perspectiva del cuerpo, argumenta Coll-Planas, conduce a una concepción voluntarista del género y la sexualidad como elecciones racionales e individuales, lejos de los constreñimientos de la materialidad y de las poderosas estructuras sociales.

La segunda aproximación reconoce el papel central del lenguaje en la configuración de nuestros mundos, pero no descuida las condiciones materiales que condicionan los cuerpos. Se trata según el autor, de una aproximación que no olvida las múltiples y a menudo violentas ataduras de la carne y por tanto, una aproximación que invita a emprender una ética del cuidado y la vulnerabilidad. Coll-Planas ilustra estas dos aproximaciones queer sobre el cuerpo haciendo alusión, respectivamente, a las aportaciones de dos autores del Estado español: Javier Sáez y Beto/Beatriz Preciado.

Los distintos hilos desarrollados a lo largo del libro desembocan en el capítulo titulado "El nudo", una metáfora apropiada para definir lo que el libro consigue. Los argumentos de Coll-Planas van construyendo un nudo que evidencia las complejas y polivalentes relaciones entre cuerpo, lenguaje, género, violencia y transformación social. Evidencian un nudo, por ejemplo, entre la demanda radical de libertad y 
la necesidad de generar ordenamientos y limites que prevengan que dicha libertad se constituya en nuevas formas de dominación; un nudo entre la transgresión y la formulación de proyectos políticos viables y vivibles para diversos sujetos violentados.

Al final del día, La carne y la metáfora: Una reflexión sobre el cuerpo en la teoría queer no busca ofrecer respuestas definitivas ni vender grandes teorias. Buscar mostrar tensiones, advertir e iluminar matices, poner en contacto, señalar efectos teóricos y políticos. A mi juicio, el gran mérito del libro es la construcción de problemas interesantesnecesarios y necesarios. Problemas que nuestros tiempos, nuestros cuerpos y nuestros contextos, nos urgen a abordar. Preguntas que han permanecido soterradas y que son medulares para los proyectos políticos y teóricos que están por venir.

En esta linea, uno de los problemas centrales que Coll-Planas señala es la presencia de un cierto tipo de "liberalismo queer (dominante en ciertos contextos) que hace buen juego con el capitalismo avanzado y por momentos, parece mimetizarse en las mismas lógicas de poder que pretende combatir.

Si bien esta denuncia es acertada y necesaria, considero que el texto haría más justicia a los diversos activismos y teorizaciones queer si analizara con mayor detalle sus aportaciones y diera espacio al análisis de los complejos matices que les componen. La crítica que realiza Coll-Planas a la obra de Beto/Beatriz Preciado, aunque atinada en muchos momentos, en otros parece mostrar esta carencia de matices y caer en una simplificación de los argumentos analizados.

Por otro lado, parte de la respuesta que se puede dar a la denuncia de prácticas queer que enfatizan el carácter discursivo y metafórico del cuerpo se encuentra, a mi juicio, en el plano histórico-dialógico, mirada que se encuentra mayoritariamente ausente en el libro. Una apreciación longitudinal permite evidenciar que el énfasis en el discurso de la mirada queer es una reacción al materialismo naturalizador que se sabe que ha tenido nefastas consecuencias para las luchas de la sexualidades marginales, una forma de cuestionar una supuesta verdad material del sexo/género que ocultaba el plano simbólico y sociopolítico en la que se configura.

Los estudios de retórica podrían confirmar que, para poder hacer un contrapeso argumental, especialmente frente a una posición tan arraigada en el sentido común, es necesario hacer una afirmación contundente e inclusive hiperbólica. Medias tintas no logran hacer 
discusión. Así, visto desde un punto de vista dialógico, el énfasis discursivo en la comprensión del cuerpo no deja de ser necesario. El problema ocurre, precisamente, cuando esta posición se reifíca y deja de verse en un contexto argumental, dialógico, histórico. Esta lectura empobrecida da lugar al idealismo que Coll-Planas denuncia.

Y esto nos conduce a otro elemento que parece estar ausente en el libro. Si bien la advertencia del riesgo de un queer-chic y consumible tiene una pertinencia global, las críticas de Coll-Planas parecen con frecuencia estar dirigidas a un contexto muy específico del activismo español y barcelonés (esto se hace notar especialmente en el epílogo). Este rasgo es una espada de doble filo. Por una parte, muestra una perspectiva parcial y situada que responde a su contexto y habla desde unas coordenadas identificables. De hecho, en ciertos momentos el tono del libro adquiere una textura poco académica, para dar la impresión de que Coll-Planas ha tomado la palabra en una asamblea o en una acalorada reunión de activistas. Se percibe que conoce con familiaridad a muchas y muchos de sus interlocutores y que incluso retoma en estas páginas, discusiones que pudieron quedar inconclusas la noche anterior. Esto muestra una reflexión teórica encarnada que se encuentra a medio camino entre la academia y el activismo.

Sin embargo, por otra parte este gesto corre el riesgo de hacer una critica poco sensible a las condiciones de otros contextos, fuera pero no muy lejos de ese círculo. Por ejemplo, un punto interesante de esta discusión reside en que, mientras en ciertos contextos (mayoritariamente europeos y anglosajones) hay que advertir sobre los riesgos de este idealismo (hay que recordar la materialidad olvidada), en otros contextos fuertemente biologicistas y medicalizados, es necesario cuestionar la materialidad naturalizada y mostrar su costura discursiva.

Al margen de estos elementos que quedan para el debate, La carne y la metáfora: Una reflexión sobre el cuerpo en la teoría queer es un valioso argumento en contra de la comprensión del cuerpo como objeto de producción y consumo, contra la banalización de la violencia física y el olvido de los constreñimientos de la carne que condicionan nuestras vidas. Es sobre todo, un diálogo, una conversación en el sentido de que interactúa con el lector, le hace preguntas continuamente y le conmina a hacer cosas para enriquecer el intercambio.

Es una conversación también en el sentido en que convoca a voces variopintas (académicas, artísticas, activistas), a miradas diversas y les pone a discutir sobre asuntos comunes. Como la conversación 
cotidiana, va y viene, salta ágil entres los temas, entra y sale, duda, revira, avanza, se apasiona, afirma. Hace continua referencia a la vida de todos los días. Alude a las notas del periódico, lo mismo que a fuentes sociológicas y filosóficas.

Es además, un libro escrito desde la sencillez y la modestia pero sin dejar de ser lúcido y audaz, una combinación poco frecuente en nuestro tiempo. Ello hace que el libro tenga interés no solo para quienes están inmersos en las discusiones más especializadas sobre cuerpo y género, sino también para quienes desean acercarse a la teoría queer y las perspectivas construccionistas sobre el sexo/género (en las que a menudo proliferan páramos confusos y discursos crípticos).

Otro mérito importante del texto es que constituye un trabajo de pensamiento propio, de autonomía intelectual. No pretende subirse gratuitamente al barco de ninguna moda intelectual, ni asumir una postura fácil en un terreno previamente repartido. Genera un singular punto de vista, una voz particular en el debate, una posición propia. Desde esta posición, el libro invita a escuchar al otro, a abrirnos al diálogo, a dejar atrás poses prepotentes que generan divisiones maniqueas entre una masa idiotizada y un sector pequeño de activistas iluminados y transgresores que se asumen a la vanguardia.

Se trata en suma, de un llamado a reconocer nuestra fragilidad, nuestra vulnerabilidad, nuestra dependencia y a incorporarles a los proyectos políticos. Un diálogo que invita a reconocer las fuerzas contradictorias que nos atraviesan. Una conversación con un interlocutor lúcido, comprometido y apasionado; una de esas conversaciones necesarias para movilizar y enriquecer los futuros colectivos.

\section{Cómo citar esta reseña}

Martínez-Guzmán, A. (2014). Reseña del libro La carne y la metáfora: una reflexión sobre el cuerpo en la teoría queers, por G. Coll-Planas. Universitas Humanística, 78, 333-338. http://dx.doi.org/10.11144/Javeriana.UH78.cmrs 